
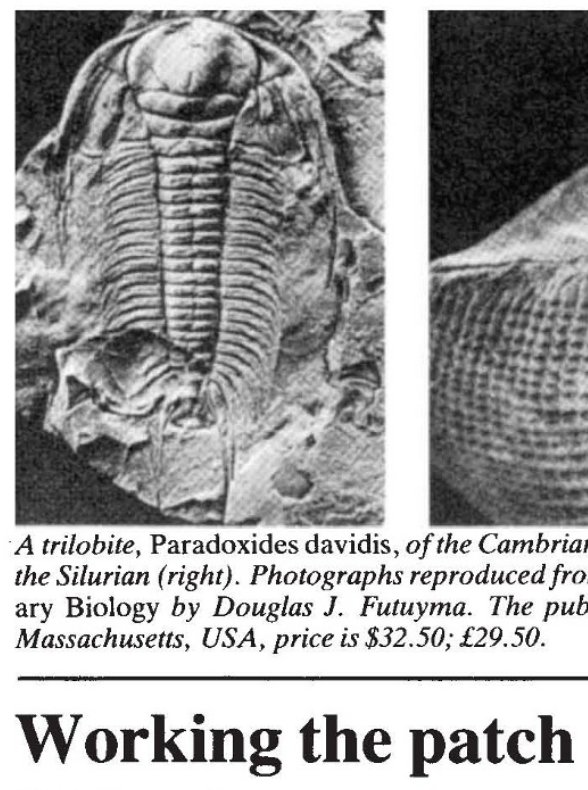

A trilobite, Paradoxides davidis, of the Cambrian (left) and a brachiopod, Gotatrypa orbicularis, of the Silurian (right). Photographs reproduced from the newly published second edition of Evolutionary Biology by Douglas J. Futuyma. The publishers are Sinauer Associates, Inc., Sunderland, Massachusetts, USA, price is $\$ 32.50 ; £ 29.50$

\section{Working the patch}

\section{C.J. Barnard}

Foraging Theory. By David W. Stephens and John R. Krebs. Princeton University Press: 1987. Pp.247. Hbk\$40, £25.10; pbk $\$ 14.50, £ 9.10$

Optimality modelling in evolutionary biology has not had an altogether smooth ride. This has had little to do with the actual merits or otherwise of optimization models, but a lot to do with the perception of what they set out to achieve. Interpreted naively (or perversely) the notion of optimality appears to be simplistic, implying an unlikely state of perfection in a world shaped by chance and natural selection. Why it implies nothing of the sort has been spelled out often enough. But entrenched misunderstanding dies hard, and one of the purposes of Foraging Theory is to take the high ground in the advocacy and defence of the optimality approach. This it does with considerable skill. Foraging behaviour has proved by far the most fertile ground for the development of optimization models, partly because the concepts and mathematics of economic decision theory translate easily into models of choice by predators, and partly because foraging behaviour is richly amenable to controlled investigation in the laboratory.

The book begins with the fundamental components of optimization models and the development of basic average rate maximizing models of prey selection and patch exploitation from Holling's disc equation. Although the discussion quickly becomes punctuated with mathematics, the crisp and lucid text always keeps the reader in touch with the arguments and the flow is helped greatly by boxes containing mathematical derivations and explanatory asides.

The main part of the book is concerned with elaboration of the basic models. In their simple form, the models are effectively unconstrained, assuming complete knowledge of the environment, unrestricted travel, instant recognition of prey and so on. The power of the approach is that biologically interesting features such as physiological constraints, trade-offs between competing activities and learning rules can be incorporated into the models as relatively digestible mathematical functions which allow the generation of precise and often counter-intuitive predictions.

Even with these modifications, however, the models still have some unwelcome limitations. They assume, for instance, that the world is completely certain and predictable, and that the optimal policy for the forager does not change as a function of its previous decisions. The chapter on risk-sensitive foraging injects some stochasticity into the forager's world and looks at choices based on probability distributions rather than certainties. That on dynamic optimization allows decision variables to depend on contingencies such as body size, past experience or estimates of future success which may themselves depend on the outcome of past decisions. In three final chapters the authors discuss the emerging interest in mechanisms (rules of thumb) that animals use in solving foraging problems, review the criteria for testing foraging models, and rehearse the main arguments and counter-arguments about the usefulness and validity of the optimality approach.

Foraging Theory is a tour de force of theoretical biology, written with care and precision by authors who thoroughly understand their subject. If anyone still seriously thinks that optimization models are "...naive, vacuous, tautological or just plain wrong..." (p. 206) they should read this book. I doubt they will think so once they have.

C.J. Barnard is a Lecturer in the Department of Zoology, University of Nottingham, Nottingham NG7 2RD. UK.

\section{Supplying the facts}

\author{
Murdoch S. Baxter
}

Environmental Radioactivity From Natural, Industrial, and Military Sources, 3rd Edn. By Merril Eisenbud. Academic: 1987. Pp.475. \$55, £41.

Most of the books reviewed in these pages are on specialized topics about which the average reader has little knowledge and hence no wish to pontificate. This text is a ready exception - every Nature reader, everyone even, has an opinion of some kind about nuclear reactors, nuclear weapons, nuclear discharges and their environmental and medical effects. Yet this also is a specialist field of science, needing detailed knowledge and understanding to support one's opinions. That, alas, most views on nuclear matters expressed nowadays are not validated by such knowledge is no fault of Merril Eisenbud, who, for 24 years, has provided a textbook containing the basic facts and principles needed for sensible entry into the nuclear debate.

This, the third edition of Environmental Radioactivity, continues Eisenbud's contribution towards divorcing fiction from fact. As before the emphasis is on principles, the quality is high, the information concise, and the discussion powerful and balanced. Because Eisenbud is an authority of long-standing, he provides not only a current but also an historical view of the nuclear scene, and is well able to put events into their proper perspective. Happily, publication was sufficiently recent to allow inclusion, within the main text, of a full summary and discussion of the nuclear accident at Chernobyl in 1986, without which the book would clearly have been devalued.

There are some specialists who regard natural radioactivity as being of at least equal scientific and social importance to the artificial forms emanating from nuclear power plants, weapons and other technologies. Natural radioactivity is, after all, used in dating geological samples and archaeological artefacts; its heat output has helped drive evolutionary processes within the planet; its component nuclides provide tracers to study rates and mechanisms of natural processes; and its associated flux of ionizing radiation generally produces a radiation dose far in excess of that from man-made inputs. Eisenbud largely ignores this academic dichotomy - this is not a book which gives full weight to the naturally occurring radionuclides. Rather it concentrates upon artificial radioactivity: nuclear reactors, nuclear fuel reprocessing, nuclear weapons, environmental dispersion of radioactive waste products, nuclear waste management, nuclear fallout (short-term and 